\title{
Choroid plexus dysfunction impairs beta-amyloid clearance in a triple transgenic mouse model of Alzheimer's disease
}

\section{Ibrahim González-Marrero', Lydia Giménez-Llort' ${ }^{2}$, Conrad E. Johanson ${ }^{3}$, Emilia María Carmona-Calero', Leandro Castañeyra-Ruiz' ${ }^{1}$, José Miguel Brito-Armas ${ }^{4}$, Agustín Castañeyra-Perdomo ${ }^{1}$ and Rafael Castro-Fuentes ${ }^{4}$ *}

${ }^{1}$ Department of Human Anatomy, School of Medicine, University of La Laguna, Tenerife, Spain

2 Institute of Neurosciences and Department of Psychiatry and Forensic Medicine, Autonomous University of Barcelona, Barcelona, Spain

${ }^{3}$ Department of Neurosurgery, Alpert Medical School at Brown University, Providence, Rhode Island, USA

${ }^{4}$ Department of Physiology, School of Medicine, University of La Laguna, Tenerife, Spain

\section{Edited by:}

Carlos Spuch, Institute of

Biomedical Research of Vigo (IBIV),

Spain

Reviewed by:

Joana Angélica Loureiro, Faculdade de Engenharia da Universidade do

Porto, Portugal

Carlos Gustavo Perez-Garcia, The

Salk Institute, USA

*Correspondence:

Rafael Castro-Fuentes, Department of Physiology, School of Medicine, University of La Laguna, Campus de Ciencias de la Salud, E-38200,

Tenerife, Canary Islands, Spain e-mail: jrcastro@ull.edu.es
Compromised secretory function of choroid plexus (CP) and defective cerebrospinal fluid (CSF) production, along with accumulation of beta-amyloid (A $\beta$ ) peptides at the blood-CSF barrier (BCSFB), contribute to complications of Alzheimer's disease (AD). The AD triple transgenic mouse model (3xTg-AD) at 16 month-old mimics critical hallmarks of the human disease: $\beta$-amyloid $(A \beta)$ plaques and neurofibrillary tangles (NFT) with a temporal- and regional-specific profile. Currently, little is known about transport and metabolic responses by $\mathrm{CP}$ to the disrupted homeostasis of CNS A $\beta$ in AD. This study analyzed the effects of highly-expressed AD-linked human transgenes (APP, PS1 and tau) on lateral ventricle CP function. Confocal imaging and immunohistochemistry revealed an increase only of $A \beta 42$ isoform in epithelial cytosol and in stroma surrounding choroidal capillaries; this buildup may reflect insufficient clearance transport from CSF to blood. Still, there was increased expression, presumably compensatory, of the choroidal $A \beta$ transporters: the low density lipoprotein receptor-related protein 1 (LRP1) and the receptor for advanced glycation end product (RAGE). A thickening of the epithelial basal membrane and greater collagenIV deposition occurred around capillaries in CP, probably curtailing solute exchanges. Moreover, there was attenuated expression of epithelial aquaporin-1 and transthyretin (TTR) protein compared to Non-Tg mice. Collectively these findings indicate CP dysfunction hypothetically linked to increasing $A \beta$ burden resulting in less efficient ion transport, concurrently with reduced production of CSF (less sink action on brain $A \beta$ ) and diminished secretion of TTR (less neuroprotection against cortical A $\beta$ toxicity). The putative effects of a disabled CP-CSF system on CNS functions are discussed in the context of AD.

Keywords: Alzheimer disease, 3xTg-AD mice, choroid plexus, dysfunction, amyloid- $\beta$, collagen-IV, transthyretin, aquaporin-1

\section{INTRODUCTION}

Alzheimer's disease (AD) is age-related neurodegeneration characterized by plaques that consist mainly of amyloid- $\beta$ $(\mathrm{A} \beta$ ) peptides and neurofibrillary tangles (NFT) containing hyperphosphorylated tau protein. These protein distortions contribute to disrupted synapses and neurotransmission, progressive neuronal death, memory impairment, and cognitive disturbances (Church et al., 2014). In vitro and in vivo studies suggest that excessive $A \beta$ peptides, at least in part, are causative or exacerbative agents in $\mathrm{AD}$ pathogenesis (Wang et al., 2006). Brain $A \beta$ peptides of $40(A \beta 40)$ or $42(A \beta 42)$ amino acids are produced, with $\mathrm{A} \beta 42$ being more aggregation prone (Thinakaran and Koo, 2008).

$A \beta$ peptides are generated from transmembrane amyloid precursor protein (APP) by $\beta$-secretase and $\gamma$-secretase in the endoplasmic reticulum, Golgi apparatus, and endosomallysosomal pathway (Selkoe, 2001; LaFerla et al., 2007). This
$\mathrm{A} \beta$-producing amyloidogenic pathway is active when APP has mutations at the cleavage sites by $\beta$ - secretase or $\gamma$-secretase (Haass et al., 1995; Wolfe et al., 1999). In contrast, $\alpha$-secretase cleaves APP within the A $\beta$ domain, precluding the generation of $A \beta$ in normal APP metabolism. While extracellular $A \beta$ aggregation has long been considered as a key culprit in $\mathrm{AD}$ onset, intracellular $A \beta$ accumulation is detected in neurons prior to the appearance of extracellular deposits (Wirths et al., 2001; Youmans et al., 2012) and is associated with cytotoxicity, dysfunction of organelles, and neurodegeneration (Bayer and Wirths, 2010).

While the rare autosomal dominant familial AD is mostly due to overproduction of $A \beta$ (O'Brien and Wong, 2011) or enhancing $\mathrm{A} \beta$ protofibril formation, far more common is the late-onset sporadic $\mathrm{AD}$ ( $\mathrm{SAD}$ ), thought to be caused, in part, by decreased clearance of the $\mathrm{A} \beta$ peptide from the CNS (Dorfman et al., 2010; Mawuenyega et al., 2010; Silverberg et al., 2010a). Thus, the 
deregulation of $\mathrm{A} \beta$ clearance pathways in brain and at CP-CSF may be a central disease event in some $\mathrm{AD}$ cases.

Maintenance of equilibrium in volume and composition of CSF is vital for normal brain function, ensuring an optimal environment for neurons. Thus the choroid plexus (CP) part of the blood cerebrospinal fluid barrier (BCSFB) also mediates secretion of proteins and various processes that clear substances from the CSF, blood or vice versa (Balda and Matter, 1998; Al-Sarraf et al., 2007; González-Marrero et al., 2013). CP has traditionally been associated with active secretion of CSF into the cerebral ventricles. Secretion of CSF is a cardinal function of CP. In CNS, AQP-1, a water channel for high osmotic water permeability, is expressed mainly in the apical membrane of the ventricular CP (Boassa and Yool, 2005) and regulates formation of CSF. Noteworthy, $>90 \%$ of the transthyretin (TTR) in CSF is synthesized within CP (Serot et al., 1997). TTR is the hallmark protein synthesized by $\mathrm{CP}$; its level in the epithelium and CSF reflect the health of the BCSFB. The main carriers for $A \beta$ transport across BBB from brain-to-blood, and blood-to-brain, are lipoprotein receptor-related protein (LRP1) and the receptor for advanced glycation end-products (RAGE), respectively. $A \beta$ transporters in $\mathrm{BBB}$ endothelium are also found in $\mathrm{CP}$ epithelium, e.g., LRP1 (Pascale et al., 2011), megalin/LRP2, P-gp and RAGE (Hammad et al., 1997; Deane et al., 2003; Serot et al., 2003a; Crossgrove et al., 2005).

Continuous removal of $A \beta$ species from CNS is important for preventing potentially neurotoxic accumulation in brain interstitial fluid (ISF) and CP. Since CP directly connects CSF with the ISF, the $A \beta$ in the brain extracellular space can freely enter CSF and be transported at the BCSFB. Increasing data for animals support the notion that compromised function of $\mathrm{CP}$ and defective CSF production and turnover (Chiu et al., 2012), with diminished clearance of the $A \beta$ peptides normally produced in brain, may be a mechanism implicated in the exacerbation of $\mathrm{SAD}$ (Silverberg et al., 2001, 2003; Serot et al., 2003b; Johanson et al., 2008; Wostyn et al., 2011).

Much understanding of how $\mathrm{A} \beta$ pathology develops has been driven by studies in animal models, which lacks proper reflection of the human disease, e.g., choroidal transport mechanisms and CSF homeostasis (Johanson et al., 2004; Spector and Johanson, 2013). Although there is no model capturing all the hallmarks of $\mathrm{AD}$, it is possible to model $\mathrm{A} \beta$ deposition (albeit with cautionary limitations) when comparing to human metabolic and transport counterparts. The most popular animal models of $\mathrm{AD}$ are transgenic mice expressing human genes with mutations leading to familial AD.

Adult 3xTg-AD mice, harboring PS1/M146V, APPSwe and tauP301L human transgenes, is an animal model that mimics many critical hallmarks of AD (Oddo et al., 2003b). Adult 3xTg$\mathrm{AD}$ displays cognitive deficits and other behavioral alterations at ages when overt neuropathology is not yet observed, although intraneuronal amyloid $A \beta$-peptide accumulation and synaptic (cholinergic) deficits are already being described at 6 months of age (Oddo et al., 2003b; Hedberg et al., 2010; Sterniczuk et al., 2010). Adult 3xTg-AD progressively develops $A \beta$ plaques and NFT from 12 months, with temporal- and regionalspecific profiles closely imitating their development in human
AD (Oddo et al., 2003a,b). Currently, little is known about the spectrum of transporter and metabolic responses by $\mathrm{CP}$ to the disrupted $\mathrm{CNS}$ homeostasis in $\mathrm{AD}$; or reciprocally, how $\mathrm{CP}$ malfunctions may contribute to (exacerbate) $\mathrm{AD}$ neuropathology.

We have sought to determine whether the pathological accumulation of CNS A $\beta$ in 3xTg-AD mice have repercussions in the functional protein expression of CP. Moreover, because compromised metabolic functions of $\mathrm{CP}$ and defective CSF production (turnover) may be linked to worsening $\mathrm{SAD}$, we decided to ascertain whether $3 \mathrm{xTg}-\mathrm{AD}$ is useful to study the role of $\mathrm{CP}$ in $\mathrm{AD}$.

\section{MATERIALS AND METHODS ANIMAL MODEL OF AD}

3xTg-AD mice harboring three mutant genes: beta-APP (APPswe), presenilin-1 (PS- 1M146V) and tauP301L, and the corresponding wild type mice were provided by Dr. Lydia Giménez-Llort (Autonomous University of Barcelona, Spain). Eight $3 \times \mathrm{xTg}-\mathrm{AD}$ mice and eight non-transgenic control mice (Non-Tg), 16 month-old, were used. Tail DNA from WT and $3 \mathrm{xTg}-\mathrm{AD}$ mice was genotyped to confirm the absence or presence of APP, PS1 and tau transgenes in Non-Tg and $3 \mathrm{xTg}-\mathrm{AD}$ mice, respectively. Moreover the presence of senile plaques in hippocampus and cerebral cortex was confirmed by Congo red and thioflavin-S. Mice were kept at a constant temperature of $21 \pm 2^{\circ} \mathrm{C}$ and $55 \pm 8 \%$ relative humidity in light-dark 12-12 h. All experiments were conducted according to the European Directive 2010/69/EU for the maintenance and use of laboratory animals, which were approved by the Committee of Animal Use for Research at the University of La Laguna. The number of animals used, as well as stress and suffering of these subjects during handling and experimentation was minimized.

\section{IMMUNOFLUORESCENCE}

To study lateral ventricle $\mathrm{CP}$, confocal microscopy was used. Brains were perfused transcardially by PBS $0.1 \mathrm{M}$ followed by fixative (4\% paraformaldehyde in PBS $0.1 \mathrm{M} \mathrm{pH} 7.4$ ), embedded in paraffin and sectioned at $7 \mu \mathrm{m}$. After deparaffinization and rehydration, tissue sections were treated with $10 \mathrm{mM}$ citrate buffer, $\mathrm{pH} 6$, at $85^{\circ} \mathrm{C}$ for $20 \mathrm{~min}$. Slides were treated $30 \mathrm{~min}$ with PBS containing $3 \%$ bovine serum albumin to block nonspecific binding. After washing in PBS $0.1 \mathrm{M} \mathrm{pH} 7.4$, sections were incubated overnight at $4^{\circ} \mathrm{C}$ with appropriate primary antibody: rabbit polyclonal anti- amyloid- $\beta$ 1-40 (ABCAM, 1:500); rabbit polyclonal anti-amyloid- $\beta$ 1-42 (Abbiotec, 1:200); rabbit polyclonal anti-low density LRP1 (Sigma-Aldrich, 1:200); rabbit polyclonal anti-receptor for advanced glycation end-products (Sigma-Aldrich, 1:400); rabbit monoclonal anti-aquaporin 1 (ABCAM, 1:200); rabbit polyclonal anti-transthyretin (Dako, 1:200). After washing, Cyanine 3 (Сy3) (red) goat anti-rabbit IgG conjugate antibodies (Invitrogen) were used as secondary antibodies for immunofluorescence. Nuclei were stained with 4'6' diamidino-2-phenylindole (DAPI). After 3 washes, samples were mounted in Vectashield Medium (Vector Laboratories Inc) for viewing by confocal microscopy (FV 1000 Olympus). 


\section{COLLAGEN-IV IMMUNOHISTOCHEMISTRY}

CP collagen-IV was studied using light microscopy. Sections were treated as explained for confocal microscopy, but after hot citrate buffer they were washed with distilled water and quenched with $3 \%$ hydrogen peroxide for $10 \mathrm{~min}$ at room temperature to eliminate endogenous peroxidase activity. As a primary antibody, rabbit polyclonal anti-collagen type IV (ABCAM, 1:500) was used. Goat anti-rabbit IgG conjugate antibodies (Invitrogen) were used as secondary antibodies. In light microscopy, the DAKO StreptABC complex/HRP Duet, Mouse/Rabbit procedure was used and the peroxidase reaction product visualized with diaminobenzidine.

\section{QUANTIFICATION OF IMMUNOSTAINING}

From each animal/group we obtained near 60 slices of CP of lateral ventricle. To study each antibody we used 7-8 slices. The intensity of immunostaining was measured in whole CP present in the slice. Fluorescence intensities from images were semiquantitatively analyzed by densitometry. Immunohistochemistry slides were converted to digital images by using an LEICA DMRB photomicroscope with an LEICA DC 300 F camera (Germany) as 8-bit acquisitions of color. Image analysis was completed in Image J (v. $1.43 \mathrm{u}, \mathrm{NIH}$, Bethesda, MD, USA). The "Mean Gray Value" was measured for all stained tissue. This value gives the average stain intensity in gray scale units for all threshold pixels.

\section{STATISTICAL ANALYSIS}

A one-way ANOVA was used for data comparison between 3xTg$\mathrm{AD}$ and Non-Tg mice. ANOVA was conducted with IBM SPSS statistic 19 software where data were considered as statistically significant at $p<0.01$.

\section{RESULTS AMYLOID-BETA DISTRIBUTION IN CP OF 3xTg-AD AND NON-Tg MICE}

$A \beta$ is a short peptide generated from APP with two main breakdown products, $A \beta 40$ and $A \beta 42$. Here we examined these peptides in different compartments related to $\mathrm{CP}$ in $3 \mathrm{xTg}-\mathrm{AD}$ and Non-Tg mice. Also is included a schematic summary of their distribution in lateral ventricles, epithelial cells, stroma and blood vessels (Figure 1E).

Confocal microscopy images revealed a strong staining of stroma and vessels of $\mathrm{CP}$ and a moderate cytosolic signal with anti-A $\beta 40$ (Figures 1A,B). We found reduced $A \beta 40$ expression in cytosol, stroma and vessels of $\mathrm{CP}$ of $3 \mathrm{xTg}-\mathrm{AD}$ vs. Non-Tg mice. The difference observed in $\mathrm{A} \beta 40$ staining was greater in the stroma surrounding blood vessels than in CP epithelium. A reduced $\mathrm{A} \beta 40$ expression was detected in $\mathrm{CP}$ stroma surrounding blood vessels and in CP epithelium from 3xTg-AD vs. Non-Tg mice (Figure 1F; ${ }^{*} p<0.013 \mathrm{xTg}-\mathrm{AD} v s$. Non-Tg mice).

Regarding $\mathrm{A} \beta 42$, staining revealed differences in signal strength and distribution. Non-Tg mice presented a CP epithelium with $\mathrm{A} \beta 42$ mainly cytoplasmic and specially in areas near the apical pole (Figure 1C); in 3xTg-AD mice, $\mathrm{A} \beta 42$ distributed uniformly through out the cytosol (Figure 1D). Is also important to point out that $\mathrm{A} \beta 42$ had a more than a two-fold increased expression in stroma of $3 \mathrm{xTg}-\mathrm{AD}$ mice compared to the weak expression in Non-Tg mice (Figure 1F; ${ }^{*} p<0.013 \mathrm{xTg}-\mathrm{AD}$ vs. Non-Tg mice). Also, vessels lacked $\mathrm{A} \beta 42$ staining in Non-Tg animals (Figure 1C).

\section{LRP1 AND RAGE EXPRESSION IN CP EPITHELIUM}

LRP1 and RAGE are the main carriers for $A \beta$ transport across BBB from brain-to-blood, and blood-to-brain, respectively. Therefore, the next step was to analyze expression of these transporters in $\mathrm{CP}$ of the 3xTg-AD and Non-Tg mice. LRP1 was expressed on cytoplasm of epithelial cells in Non-Tg animals (Figure 2A) and in 3xTg-AD mice (Figure 2B). Cytosolic LRP1 protein presented a two-fold increase in 3xTg-AD compared Non-Tg (Figure 2E). Confocal microscopy images for RAGE in CP from Non-Tg and 3xTg-AD mice are also shown (Figures 2C,D). The location of RAGE staining in both groups of animals was only cytosolic and lacked detection either in $\mathrm{CP}$ vessels or basement membrane (Figures 2C,D). We found $\sim$ four-fold cytoplasmic increase in RAGE expression in epithelial cells of $3 \mathrm{xTg}-\mathrm{AD}$ vs. Non-Tg (Figure 2E; ${ }^{*} p<0.013 x T g-A D$ vs. Non- Tg mice).

\section{COLLAGEN-IV DEPOSITION IN CP BASEMENT MEMBRANE}

$\mathrm{CP}$ is a highly vascularized structure receiving 5-10 times more blood flow than other brain regions (Szmydynger-Chodobska et al., 1994). This physiologic state of brisk blood flow would make CP more sensitive to reduced vascular perfusion. In order to link possible changes in CBF with the state of both of the vessels and basement membrane, we also examined collagen-IV expression. Figure 3 presents $\mathrm{CP}$ staining with anti-collagen type IV in Non-Tg (Figures 3A,B) and 3xTg-AD mice (Figures 3C,D). Collagen-IV is widely located only in CP epithelial cells basement membrane and the blood vessel basement membrane, a collagenIV cell staining lacked detection in whole CP. Collagen-IV labeling was $\sim$ two-fold higher in $3 \mathrm{xTg}$-AD in comparison with Non-Tg mice (Figure 3E; ${ }^{*} p<0.013 x T g-A D$ vs. Non- Tg mice).

\section{AQP-1 AND TTR EXPRESSION IN CP}

In $\mathrm{AD}$, the adverse effects of CSF stasis (decreased turnover rate) are potentiated by declining ability of CSF to inhibit formation of A $\beta$ oligomers (Serot et al., 2003b, 2012; Silverberg et al., 2003; Wostyn et al., 2011). We assessed expression of two proteins in $\mathrm{CP}$ secretory functions. These are TTR, one of the major proteins synthetized by CP, and AQP-1, a water channel transport protein involved in CSF production. TTR was located in cytoplasm of CP epithelial cells as in 3xTg-AD as in Non-Tg mice. TTR present in $\mathrm{CP}$ was significantly reduced in $3 \mathrm{xTg}-\mathrm{AD}$ compared to Non- $\mathrm{Tg}$ mice (Figures 4A,B). This expression was $>3$ fold lower in 3xTg$\mathrm{AD}$ than Non-Tg (Figure 4E; ${ }^{*} p<0.013 \mathrm{xTg}-\mathrm{AD}$ vs. Non- Tg mice).

AQP-1 expression was located on the apical membrane of $\mathrm{CP}$ epithelial cells in Non-Tg (Figure 4C) and 3xTg-AD mice (Figure 4D). While in Non-Tg mice AQP-1 staining was distributed in whole apical pole of CP epithelial cells, we observed that some epithelial cells showed a lack of AQP-1 expression on their apical membranes. The values of AQP-1 staining were $31 \%$ lower in 3xTg-AD compared to Non-Tg mice (Figure 4E). 


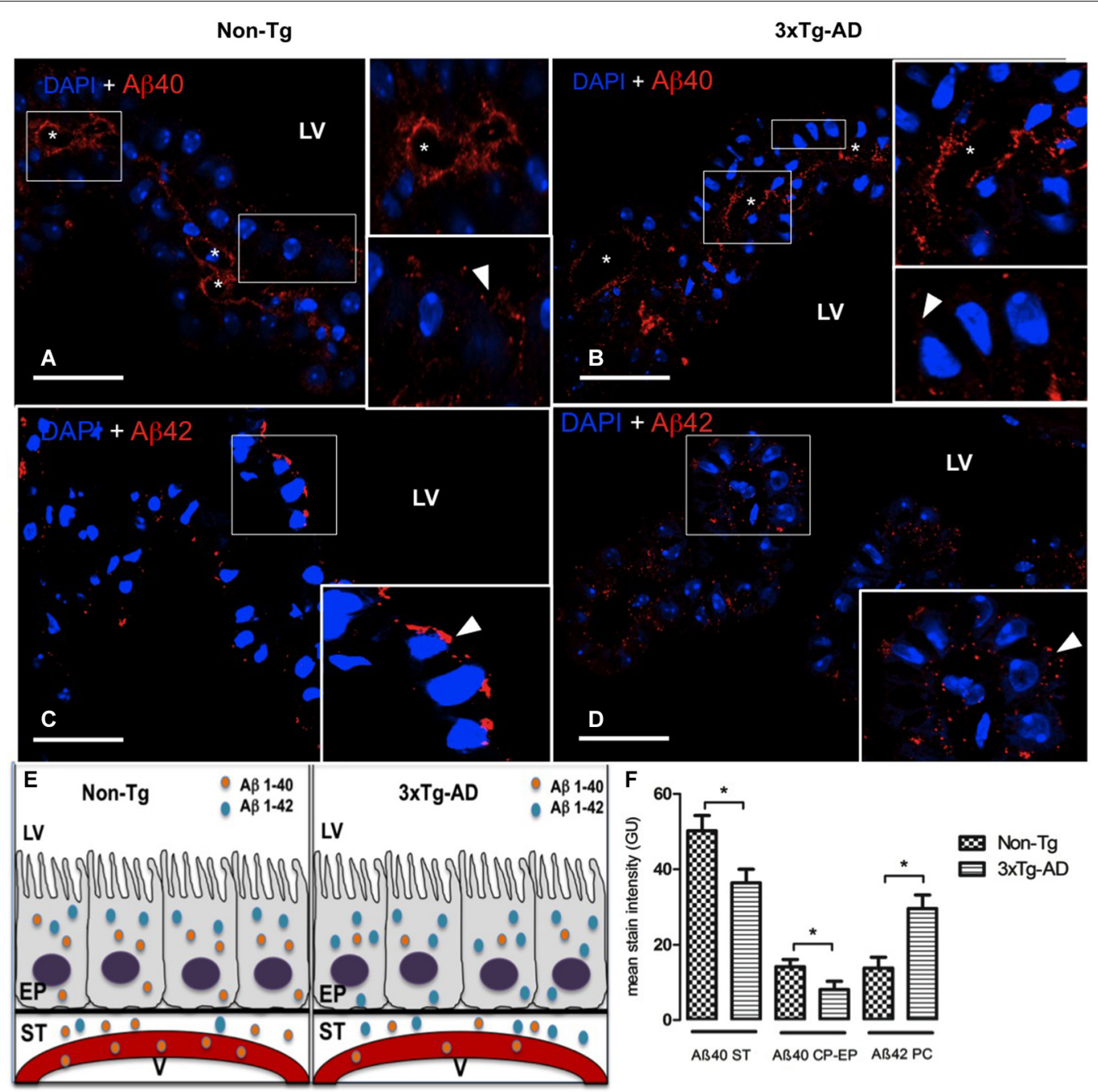

FIGURE 1 | Choroid plexus (CP) confocal microscopy images immunolabeled from Non-Tg $(A, C)$ and $3 \times T g-A D$ mice $(B, D)$ stained with anti-A $\mathbf{\beta 4 0}(\mathbf{A}, \mathbf{B})$ and anti-A $\mathbf{\beta 4 2}(\mathbf{C}, \mathbf{D})$. The asterisks show the blood vessels staining and arrowheads show the cytoplasmic staining of CP epithelial cells (CP-EP) of lateral ventricle (LV). According to figure (see also the results in text) in the left bottom (E) is also shown a scheme about the distribution of $A \beta 40$ and $A \beta 42$ in vessels (V), stroma (ST) and epithelial cells (EP) of 3xTg-AD compared to Non-Tg mice. On the right bottom (F) are presented values of stain intensitites for $A \beta 40$ and $A \beta 42$ as the means \pm SEM; $n=$ eight animals per group; * $p<0.013 \times T g-A D$ vs. Non-Tg mice. Scale bars, $30 \mu \mathrm{m}$.

\section{DISCUSSION}

3xTg-AD mice at 16 months exhibits age- related pathology similar to human $\mathrm{AD}$ (Oddo et al., 2003b). We analyzed: (i) the amount of $\mathrm{A} \beta$ fragment material in $\mathrm{CP}$ as well as the transporters that move $\mathrm{A} \beta$ into and out of $\mathrm{CP}$, (ii) the expression of collagen at transport interfaces within the BCSFB; and (iii) the effects of highly-expressed human AD-linked transgenes on the synthesis of CP functional proteins such as TTR and AQP-1.

\section{CHOROID EPITHELIAL CELL A $\beta$}

$\mathrm{A} \beta$ accumulates in $\mathrm{CP}$ of $\mathrm{AD}$ patients. Similarly, we found increased $\mathrm{A} \beta 42$ in epithelial cytoplasm of 3xTg-AD mice. Choroid cell $A \beta$ is also elevated in aging rats, various $\mathrm{Tg}$ mouse models of $\mathrm{A} \beta$, and in $\mathrm{Pb}$-treated mice. Changes in $\mathrm{CP} A \beta$ levels reflect altered homeostatic transport across the BCSFB and/or greater local synthesis of $A \beta$ in choroid cells. Excess $A \beta$ in $C P$ probably alters homeostatic functions of the BCSFB (e.g., increased barrier permeability) or compromises organic molecule transport adjustments to protect the CSF-brain interstitial environment. Toxic levels of $\mathrm{A} \beta$ in $\mathrm{CP}$ could potentially alter enzymatic reactions that carry out homeostatic functions such as forming CSF. Therefore, attention needs to be paid to $A \beta$ loading (burden) in $\mathrm{CP}$ as well as brain.

\section{A $\beta$ TRANSPORTERS IN CP}

In the $3 \times$ Tg-AD mice, we found increased LRP1 and RAGE in $\mathrm{CP}$ cytosol. AQP-1 moves between cytosol and external limiting membranes (e.g., apical) of CP to control functional activity (Kalani et al., 2012); also, LRP1 and RAGE in cytosol probably inserts into cellular membranes -also needing elucidation is 

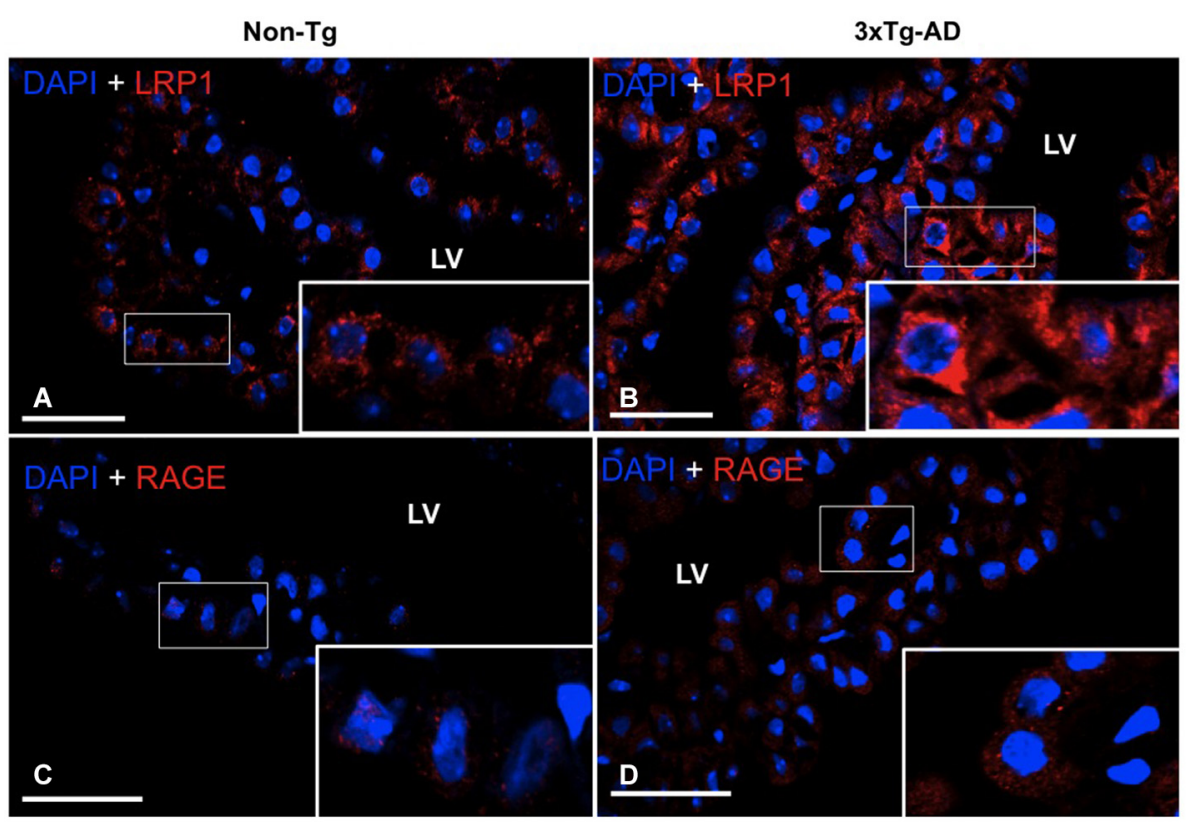

E

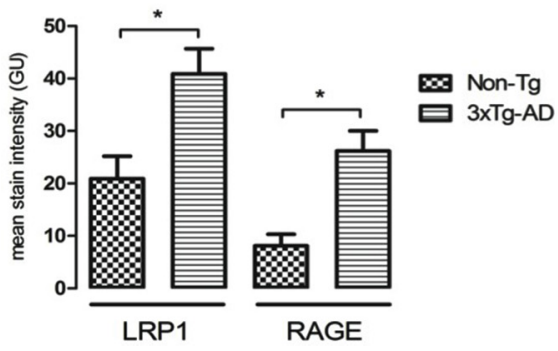

FIGURE 2 | CP confocal microscopy images immunolabeled from Non-Tg $(A, C)$ and 3xTg-AD mice (B,D) stained with anti-LRP1 (A,B) and anti-RAGE (C,D). An increase in cytoplasmic expression of LRP1 and RAGE in epithelial cells of lateral ventricle (LV) of 3xTg-AD compared to
Non-Tg mice is shown. On the left bottom (E) are represented values of stain intensitites for LRP1 and RAGE as the means \pm SEM; $n=$ eight animals per group; ${ }^{*} p<0.013 \times T g-A D$ vs. Non-Tg mice. Scale bars, $30 \mu \mathrm{m}$. how cytosolic transport proteins insert into organelles to control $\mathrm{A} \beta$ metabolism and trafficking within the cell-. Clearly, substantial $\mathrm{A} \beta$ data for $\mathrm{BBB}$ indicate that expression levels of endothelial LRP1, LRP2, P-gP and RAGE markedly affect $\mathrm{A} \beta$ burden in cortex. Similar transport/distribution principles apply to $\mathrm{BCSFB}$, in regard to clearing excess $\mathrm{A} \beta$ out of CNS.

There is increased transcription of the $A \beta$ efflux membrane transporters, LRP1 and P-gp, no change in RAGE expression and a decrease in Megalin/LRP2 at the BCSFB during normal aging in rodents (Pascale et al., 2011). Although aging CP transport phenomena mimics those of $\mathrm{AD}$, they may differ in degree of affectation. Age- dependent alterations in $\mathrm{CP} A \beta$ transporters were associated with decreased $\mathrm{A} \beta 42$ in $\mathrm{CP}$, and were reciprocal to corresponding changes in LRP1 and PgP transporter expression at the aging BBB (Silverberg et al,, 2010a,b). This suggests compensatory clearance via BCSFB of $A \beta$ in aging, even as the BBB LRP1 and P-gp transporters are failing (Pascale et al., 2011).
Contrary to non-diseased aging, we found in $3 \times \mathrm{Tg}-\mathrm{AD}$ mice elevated $\mathrm{A} \beta 42$ and increased expression of cytosolic LRP1 in CP epithelium (Figures 2B,E). Popular animal models of $\mathrm{AD}$, including $3 \mathrm{xTg}-\mathrm{AD}$, are mice overexpressing human genes with mutations that cause familial AD. These $\mathrm{Tg}$ mice overaccumulate $A \beta$ in $C P$ and brain. $A \beta 42$ is more problematic because it aggregates and promotes deposits earlier in disease than A $\beta 40$ (Iwatsubo et al., 1994). Thus, abundant in brain are $A \beta 40$ and $A \beta 2$, the first being the prevalent fragment, and the latter more amyloidogenic (Abramowski et al., 2012).

\section{A $\beta$ UPTAKE FROM CSF BY CP}

$\mathrm{CP}$ is contiguous with CSF and cerebral interstitial fluid (ISF; Johanson, 2003). Thus, A $\beta$ in brain ISF freely enters CSF (Gu et al., 2014) and flows/diffuses to nearby CP for reabsorption into choroidal venous blood. Moreover, interstitial $\mathrm{A} \beta$ drainage from brain to ventricles seems to be the major origin of $A \beta$ in CSF because changes in CSF $A \beta$ levels reflect 


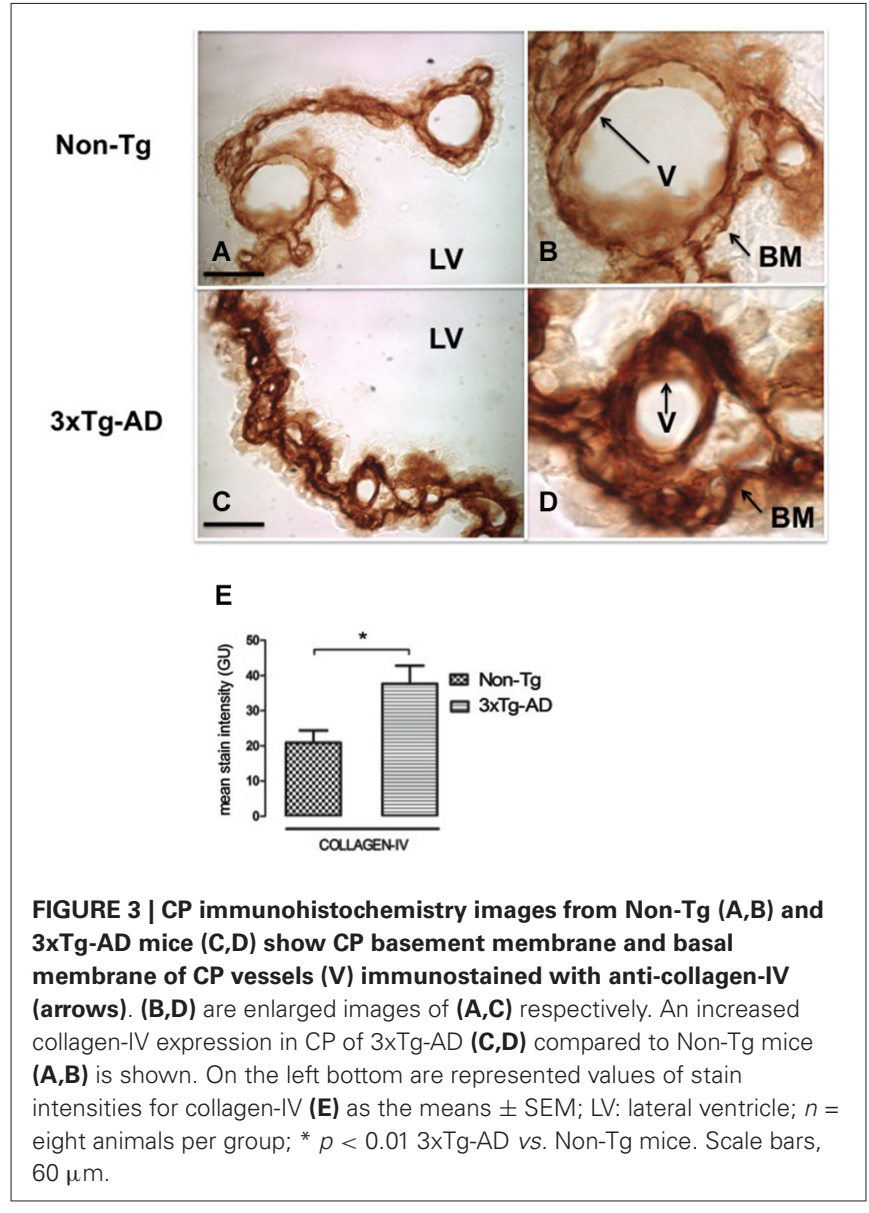

changes in brain $A \beta$ following therapeutic treatments (Lu et al., 2013). CP epithelium is exposed to several-fold higher $\mathrm{A} \beta 40$ concentrations in CSF than that of $\mathrm{A} \beta 42$ (Cirrito et al., 2003; Head et al., 2010; Borghys et al., 2014; Savage et al., 2014).

LRP1 in CP has a major role in removing $A \beta$ from CSF via clearance transport at the apical membrane. Why does $\mathrm{A} \beta 42$ accumulate in cytosol near the apical membrane? Upon transport into the choroid cell from CSF, there is probably epithelial metabolism of cytoplasmic $A \beta 40$ (Crossgrove et al., 2007) and/or efflux at the choroid cell-ISF interface into venous blood (Crossgrove et al., 2005). More needs to be known about efflux transport in the basolateral membrane because this is the final step in disposing CNS-CSF A $\beta$ into blood, thus protecting $\mathrm{CP}$ epithelium and ultimately the brain from $\mathrm{A} \beta$ toxicity. In acute $\mathrm{Pb}$-toxicity model, the decreased expression of LRP1 in CP epithelium was associated, paradoxically, with increased $A \beta$ in $C P$ (Behl et al., 2010); however, CP A $\beta$ efflux into blood was uncharacterized; a factor also affecting epithelial $\mathrm{A} \beta$ concentration.

\section{METABOLIC PROCESSING OF CP A $\beta$}

Following uptake of $A \beta$ from outside $C P$, or its enzymatic generation within the epithelium, there is processing of the amyloid peptides to minimize toxicity. Low solubility and elevated $\mathrm{A} \beta 42$ in $\mathrm{CP}$ may exceed lysosomal degradation capacity. Notably, intact lysosomes are more prevalent in fluoresceinlabeled $\mathrm{A} \beta 0$ (F-A $\beta 40)$ treated cells than in $\mathrm{F}-\mathrm{A} \beta 42$ treated cells, likely due to less F-A $\beta 40$ inability to accumulate in lysosomes (Omtri et al., 2012). Cell culture reveals substantial intracellular $\mathrm{A} \beta$ and comparably little secretion, particularly of A $\beta 42$ (Maruyama et al., 1995). Moreover, continuous uptake data suggest that, over time, $A \beta 42$ might escape degradation and start to accumulate (Fuentealba et al., 2010). All in all, CP A $\beta$ accumulation is a function of $A \beta$ metabolism as well as uptake from CSF.

Our current study shows significantly reduced $A \beta 40$ in $\mathrm{CP}$ epithelium and stroma in $3 \mathrm{xTg}-\mathrm{AD}$ vs. Non-Tg mice (Figures 1A,B,F). A $\beta 40$ impacts lysosomal integrity less because of smaller propensity to aggregate and greater susceptibility to lysosomal proteases. A $\beta 40$ clears rapidly after i.c.v. injection (Ghersi-Egea et al., 1996; Ji et al., 2001), and may also be degraded faster in CP. Interestingly, in Tg mouse lines generating $A \beta 40$ (APP47) and A 342 (APP48) in neurons, APP47 mice only show somatic $A \beta$ granules consistent with a more rapid, complete degradation of $A \beta 40$ (Omtri et al., 2012).

Our findings provide evidences $C P$ internalize $A \beta 40$ and $\mathrm{A} \beta 42$ via different mechanisms. Such regulated trafficking along distinct pathways suggests that $A \beta 40$ and $A \beta 42$ exercise differential effects on CP epithelial cells. Further studies should investigate the intracellular pharmacokinetics of $A \beta 40$ and $A \beta 42$ following uptake at the BCSFB, and evaluate the tendency of $\mathrm{A} \beta$ fragments to accumulate in cellular compartments susceptible to A $\beta$ toxicity.

\section{DO PLASMA INCREASED A $\beta$ AND SOLUBLE LRP1 ALSO AFFECT CP-CSF $\mathrm{A} \beta$ ?}

$\mathrm{A} \beta$ may enter CP from plasma as well as CSF. We show increased choroid cell $\mathrm{A} \beta 42$ immunofluorescence, punctuated in $\mathrm{CP}$ of 3xTg-AD compared with Non-Tg mice (Figures 1C,D,F). In neurologically-healthy humans and mice, a soluble LRP1 species, sLRP1, binds $>70 \%$ of vascular-circulating $A \beta$; this prevents free $A \beta$ access to brain (and presumably $C P$ epithelium; Sagare et al., 2007). In $\mathrm{AD}$ patients and Tg mice, $\mathrm{A} \beta$ binding to sLRP1 is severely compromised. This results in elevated levels of free $A \beta 40$ and $A \beta 42$ in plasma (Sagare et al., 2011) that (in addition to LRP1-mediated A $\beta$ efflux into blood) can re-enter brain via RAGE transport across BBB, and possibly CP (Deane et al., 2003; Donahue et al., 2006; Sagare et al., 2007).

RAGE transports $A \beta$ into CNS from plasma, where it may be elevated in AD (Deane et al., 2003). RAGE expression increases in neurons, astrocytes and cerebrovascular endothelial cells in an $\mathrm{A} \beta$-rich environment, seen in $\mathrm{AD}$ models and dementia (Deane et al., 2003; Choi et al., 2014). Such influx, if accelerated by elevated plasma $A \beta$ via upregulated RAGE in BBB and BCFSB, would amplify the $A \beta$-mediated pathogenic/metabolic responses. Our study does show increased cytosolic RAGE expression in $\mathrm{CP}$ epithelial cells and an $\mathrm{A} \beta 42$ increase in $\mathrm{CP}$ stroma of $3 \times T$ Tg-AD vs. Non-Tg mice (Figures 2D,E). Similarly to BBB, $A \beta 42$ accumulation in $\mathrm{CP}$ blood and stroma may induce a RAGE increase, which could lead to a significant $A \beta$ increase in CP. 


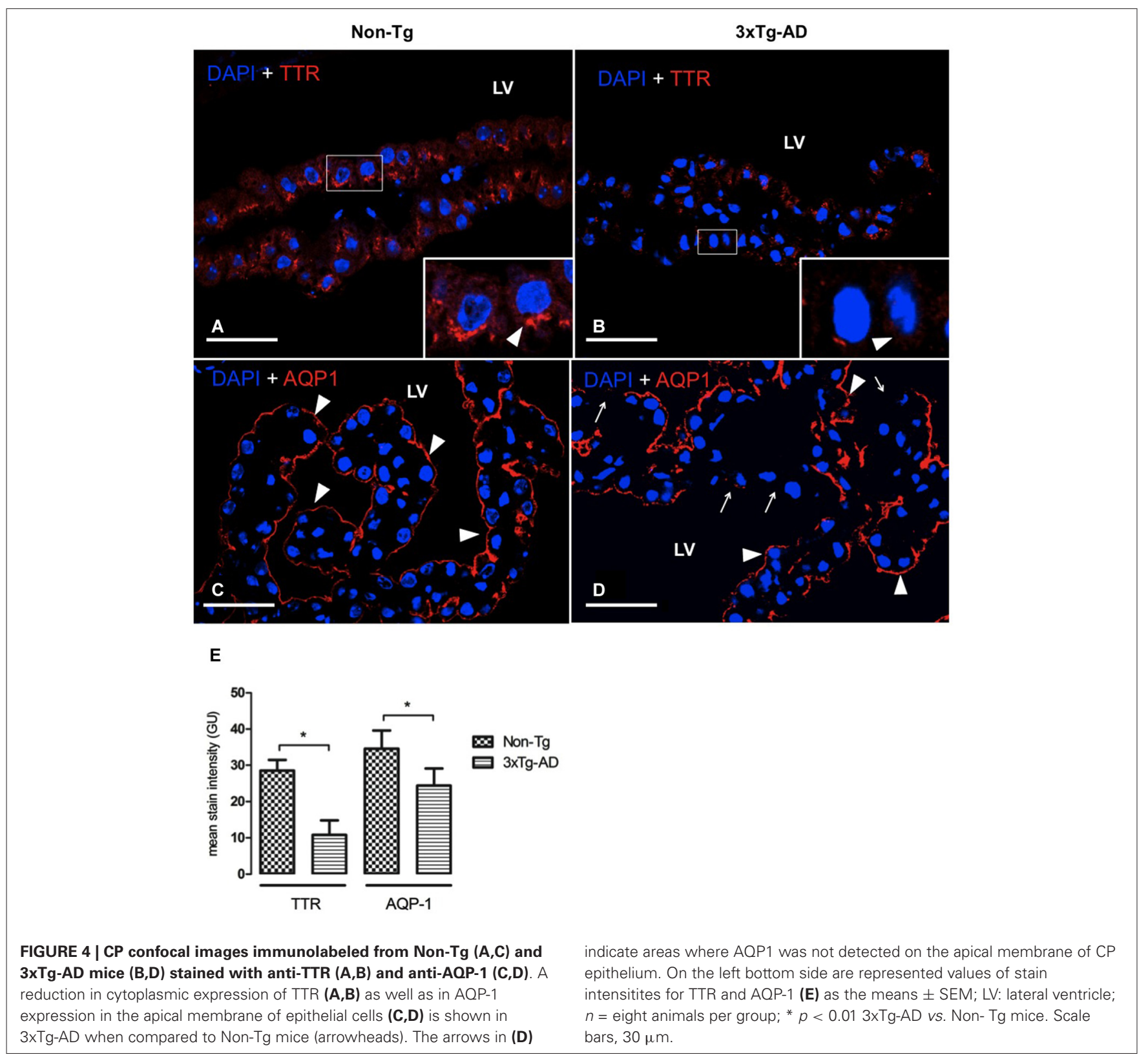

\section{ALTERED BASEMENT MEMBRANES IN THE BCSFB AND BBB OF 3xTg-AD MICE}

The basement membrane (Deane et al., 2004) thickens in the $\mathrm{BBB}$ of $3 \mathrm{xTg}-\mathrm{AD}$ mice; this thickening can modulate hemodynamic responses, microvessel integrity/permeability and molecular fluxes via transporter expression/activity in the barrier. Animal models reveal mechanisms that link reduced cerebral blood flow (CBF) to capillary state. Permanently ligated common carotid arteries in rats model chronic cerebral hypoperfusion, when CBF is reduced to $\sim 70 \%$ (Tsuchiya et al., 1992). This coincides with falling $\mathrm{CBF}$ in the hippocampus and temporal cortex in AD (Eberling et al., 1992; Ohnishi et al., 1995; Tang et al., 2012; Mattsson et al., 2014). A previous 3xTg-AD study described reduced vascular volume in brain of 11-month-old mice; BBB functional integrity was maintained even though reduced vascular volume was accompanied by accumulated collagen I/IV and a thickened vascular basement membrane (BM; Bourasset et al., 2009). Microvascular BM thickening, with more collagen-IV, has been also shown in human AD (Kalaria and Pax, 1995; Claudio, 1996); pathophysiologic analyses of transporters and fluxes in thickened BBB membranes need to be done.

$\mathrm{CP}$ is highly perfused, much greater than brain. Any dwindling of this brisk choroidal blood flow, as in AD, might impact endothelial cells and their underlying BM. In the current study, the apparent thickness of $\mathrm{BM}$ in $\mathrm{CP}$ was assessed immunohistochemically by measuring collagenIV (Farkas and Luiten, 2001). For the first time, we show significantly accumulated collagen-IV in $\mathrm{BM}$ of $\mathrm{CP}$ in $3 \mathrm{xTg}-\mathrm{AD}$ 
mice (Figures 3C-E). The exact reason for increased collagen-IV and subsequent thickening of the $\mathrm{BMs}$ in $\mathrm{AD}$, at both the capillary and epithelial BMs, needs full characterization. According to Fick's diffusion theory, a major factor affecting diffusion across biological membranes is membrane thickness. BM thickening reduces permeability (Zwolinski et al., 1948) and makes plasma ultrafiltration, CP epithelial oxygenation and CSF formation all less efficient. This idea fits our findings of lower expression of AQP-1 and TTR in CP in 3xTg-AD mice.

\section{CSF BULK FLOW ATTENUATION: REDUCED EXCRETION OF CSF A $\beta$}

Along with reduced clearance of $A \beta$ across $B B B$ with increasing age and $\mathrm{AD}$, there is also a decline in $\mathrm{A} \beta$ clearance from CNS via CSF bulk flow into the arachnoidal-venous system (Silverberg et al., 2010b; Pascale et al., 2011; Serot et al., 2011). What mechanisms underlie this phenomenon? CSF formation by CP, and its eventual turnover into the ventriculo-subarachnoid CSF system, depends upon the molecular integrity of CSF- transport enzymes and AQP-1; the expression of both are reduced in 3xTg$\mathrm{AD}$ mice, probably by toxic levels of $\mathrm{A} \beta$ in $\mathrm{CP}$. Our working model supports the notion that accumulating $A \beta 42$ in choroidal epithelium contributes to a dysfunctional BCSFB. In fact, a sequence of pathological steps that link $A \beta$ accumulation with an $\mathrm{AD}$ progression-related increase in oxidative damage, has recently been proposed (Krzyzanowska and Carro, 2012).

The necessarily high water permeability of the CP interface is made possible, in part, by AQP-1, a water channel expressed strongly at the ventricular- facing surface (Boassa and Yool, 2005). Senescent rats are less able to form CSF (Masseguin et al., 2005); a reduced AQP-1 expression in CP accompanies slower rates of CSF secretion in aging (Redzic et al., 2005). Similarly, reduced CSF secretion occurs in aging and $\mathrm{AD}$ (Johanson et al., 2008; Chen et al., 2009; Serot et al., 2012). The reduced AQP1 expression in $\mathrm{CP}$ of $3 \mathrm{xTg}-\mathrm{AD}$ mice (Figures $4 \mathrm{C}-\mathrm{E}$ ) probably impairs CP capacity to secrete CSF; consequently, the slowing of $\mathrm{CSF}$ convection would reduce $\mathrm{A} \beta$ removal from $3 \mathrm{xTg}-\mathrm{AD}$ mice CNS via ventricular bulk flow.

\section{LOWER EXPRESSION OF CP TRANSTHYRETIN: IMPLICATIONS FOR REDUCED A $\beta$ REMOVAL}

Decreased CP protein synthesis/secretion as well as slower CSF renewal accelerate the progressing neuropathology. As mentioned, some $\mathrm{CP}$ proteins interact neuroprotectively with $\mathrm{A} \beta$ and this could be the basis for altered A $\beta$ clearance; lower TTR in CSF would mean less neuroprotection afforded via enzymatic degradation of $A \beta$ and tetramer stabilization binding. TTR is a major protein synthesized and secreted by CP into CSF (Dickson et al., 1986); this tetrameric protein binds to and stabilizes soluble $A \beta$ (Tang et al., 2004). We found reduced TTR expression in $\mathrm{CP}$ of 3xTg-AD vs. Non-Tg mice (Figures 4A,B,E). Lower TTR expression in $\mathrm{CP}$ of $3 \mathrm{xTg}-\mathrm{AD}$ mice likely leads to deficiency of TTR in CSF. Decreased CSF levels of TTR occur in severe dementia and AD (Riisøen, 1988; Serot et al., 1997). Since CP is the primary source of TTR in the CNS, a CSF-deficient TTR presumably results from decreased CP synthesis/secretion in aging and AD (Stoquart-ElSankari et al., 2007). Diminishing CNS TTR has been linked to cognitive decline with age (Preston et al.,
2005). A key question is whether excess $A \beta$ in CP directly downregulates TTR expression in epithelial cells.

\section{CONCLUSIONS}

Our findings prompt consideration of identifying ways to protect or restore the gradually-failing functions of the BCSFB in the face of metabolic dysfunctions in the aging, diseased CNS. A healthy $\mathrm{CP}$ in advanced life stages would confer numerous benefits on the brain. Moreover, these results may be considered for futures pharmacological treatments in order to restore impaired functions of $\mathrm{CP}$ in $\mathrm{AD}$.

\section{ACKNOWLEDGMENTS}

The animals used in the present study come from the Spanish colony established from progenitors kindly provided by F.M. LaFerla, Institute for Memory impairments and Neurological Disorders, University of California Irvine, California, USA. All the experiments with animals were done according to the guidelines of the Ethic committee of the University of La Laguna. This work was supported by Instituto de Salud Carlos III, ISC3PI10/00283. The authors declare that they do not have any competing or financial interests.

\section{REFERENCES}

Abramowski, D., Rabe, S., Upadhaya, A. R., Reichwald, J., Danner, S., Staab, D., et al. (2012). Transgenic expression of intraneuronal $\mathrm{A} \beta 42$ but not $\mathrm{A} \beta 40$ leads to cellular $\mathrm{A} \beta$ lesions, degeneration and functional impairment without typical Alzheimer's disease pathology. J. Neurosci. 32, 1273-1283. doi: 10 1523/JNEUROSCI.4586-11.2012

Al-Sarraf, H., Ghaaedi, F., and Redzic, Z. (2007). Time course of hyperosmolar opening of the blood-brain and blood- CSF barriers in spontaneously hypertensive rats. J. Vasc. Res. 44, 99-109. doi: 10.1159/000098260

Balda, M. S., and Matter, K. (1998). Tight junctions. J. Cell Sci. 111, 541-547. doi: $10.1007 /$ springerreference_33880

Bayer, T. A., and Wirths, O. (2010). Intracellular accumulation of amyloid-beta-a predictor for synaptic dysfunction and neuron loss in Alzheimer's disease. Front. Aging. Neurosci. 2:8. doi: 10.3389/fnagi.2010.00008

Behl, M., Zhang, Y., Shi, Y., Cheng, J., Du, Y., and Zheng, W. (2010). Leadinduced accumulation of beta-amyloid in the choroid plexus: role of low density lipoprotein receptor protein-1 and protein kinase C. Neurotoxicology 31, 524532. doi: 10.1016/j.neuro.2010.05.004

Boassa, D., and Yool, A. J. (2005). Physiological roles of aquaporins in the choroid plexus. Curr. Top. Dev. Biol. 67, 181-206. doi: 10.1016/s0070-2153(05)67005-6

Borghys, H., Jacobs, T., Van Broeck, B., Dillen, L., Dhuyvetter, D., Gijsen, H., et al. (2014). Comparison of two different methods for measurement of amyloid$\beta$ peptides in cerebrospinal fluid after BACE1 inhibition in a dog model. $J$. Alzheimers Dis. 38, 39-48. doi: 10.3233/JAD-130599

Bourasset, F., Ouellet, M., Tremblay, C., Julien, C., Do, T. M., Oddo, S., et al. (2009). Reduction of the cerebrovascular volume in a transgenic mouse model of Alzheimer's disease. Neuropharmacology 56, 808-813. doi: 10.1016/j. neuropharm.2009.01.006

Chen, R. L., Kassem, N. A., Redzic, Z. B., Chen, C. P., Segal, M. B., and Preston, J. E. (2009). Age-related changes in choroid plexus and blood-cerebrospinal fluid barrier function in the sheep. Exp. Gerontol. 44, 289-296. doi: 10.1016/j.exger. 2008.12.004

Chiu, C., Miller, M. C., Caralopoulos, I. N., Worden, M. S., Brinker, T., Gordon, Z. N., et al. (2012). Temporal course of cerebrospinal fluid dynamics and amyloid accumulation in the aging rat brain from three to thirty months. Fluids Barriers CNS 9:3. doi: 10.1186/2045-8118-9-3

Choi, B. R., Cho, W. H., Kim, J., Lee, H. J., Chung, C., Jeon, W. K., et al. (2014). Increased expression of the receptor for advanced glycation end products in neurons and astrocytes in a triple transgenic mouse model of Alzheimer's disease. Exp. Mol. Med. 46:e75. doi: 10.1038/emm.2013.147 
Church, R. M., Miller, M. C., Freestone, D., Chiu, C., Osgood, D. P., Machan, J. T., et al. (2014). Amyloid-Beta accumulation, neurogenesis, behavior and the age of rats. Behav. Neurosci. 4, 523-536. doi: 10.1037/a0036433

Cirrito, J. R., May, P. C., O’Dell, M. A., Taylor, J. W., Parsadanian, M., Cramer, J. W., et al. (2003). In vivo assessment of brain interstitial fluid with microdialysis reveals plaque-associated changes in amyloid- $\beta$ metabolism and half-life. $J$. Neurosci. 23, 8844-8853. doi: 10.1007/springerreference_35677

Claudio, L. (1996). Ultrastructural features of the blood-brain barrier in biopsy tissue from Alzheimer's disease patients. Acta Neuropathol. 91, 6-14. doi: 10. 1007/s004010050386

Crossgrove, J. S., Li, G. J., and Zheng, W. (2005). The choroid plexus removes betaamyloid from brain cerebrospinal fluid. Exp. Biol. Med. (Maywood) 230, 771776.

Crossgrove, J. S., Smith, E. L., and Zheng, W. (2007). Macromolecules involved in production and metabolism of beta-amyloid at the brain barriers. Brain Res. 1138, 187-195. doi: 10.1016/j.brainres.2006.12.022

Deane, R., Du, Y. S., Submamaryan, R. K., LaRue, B., Jovanovic, S., Hogg, E., et al. (2003). RAGE mediates amyloid-beta peptide transport across the bloodbrain barrier and accumulation in brain. Nat. Med. 9, 907-913. doi: 10.1038/ nm890

Deane, R., Wu, Z., Sagare, A., Davis, J., Du Yan, S., Hamm, K., et al. (2004). LRP/amyloid beta-peptide interaction mediates differential brain efflux of Abeta isoforms. Neuron 43, 333-344. doi: 10.3410/f.1020568.235474

Dickson, P. W., Aldred, A. R., Marley, P. D., Bannister, D., and Schreiber, G. (1986). Rat choroid plexus specializes in the synthesis and the secretion of transthyretin (prealbumin). Regulation of transthyretin synthesis in choroid plexus is independent from that in liver. J. Biol. Chem. 261, 3475-3478.

Donahue, J. E., Flaherty, S. L., Johanson, C. E., Duncan, J. A. 3rd, Silverberg, G. D., Miller, M. C., et al. (2006). RAGE, LRP-1 and amyloid-beta protein in Alzheimer's disease. Acta Neuropathol. 112, 405-415. doi: 10.1007/s00401-0060115-3

Dorfman, V. B., Pasquini, L., Riudavets, M., López-Costa, J. J., Villegas, A., Troncoso, J. C., et al. (2010). Differential cerebral deposition of IDE and NEP in sporadic and familial Alzheimer's disease. Neurobiol. Aging 31, 1743-1757. doi: 10.1016/j.neurobiolaging.2008.09.016

Eberling, J. L., Jagust, W. J., Reed, B. R., and Baker, M. G. (1992). Reduced temporal lobe blood flow in Alzheimer's disease. Neurobiol. Aging 13, 483-491. doi: 10. 1016/0197-4580(92)90076-a

Farkas, E., and Luiten, P. G. (2001). Cerebral microvascular pathology in aging and Alzheimer's disease. Prog. Neurobiol. 64, 575-611. doi: 10.1016/s03010082(00)00068-X

Fuentealba, R. A., Liu, Q., Zhang, J., Kanekiyo, T., Hu, X., Lee, J. M., et al. (2010). Low-density lipoprotein receptor-related protein 1 (LRP1) mediates neuronal Abeta42 uptake and lysosomal trafficking. PLoS One 5:e11884. doi: 10 1371/journal.pone.0011884

Ghersi-Egea, J. F., Gorevic, P. D., Ghiso, J., Frangione, B., Patlak, C. S., and Fenstermacher, J. D. (1996). Fate of cerebrospinal fluid-borne amyloid $\beta$ peptide:Rapid clearance into blood and appreciable accumulation by cerebral arteries. J Neurochem 67, 880-883. doi: 10.1046/j.1471-4159.1996.67020880.x

González-Marrero, I., Castañeyra-Ruiz, L., González-Toledo, J. M., CastañeyraRuiz, A., de Paz-Carmona, H., Castro, R., et al. (2013). High blood pressure effects on the blood to cerebrospinal fluid barrier and cerebrospinal fluid protein composition: a two-dimensional electrophoresis study in spontaneously hypertensive rats. Int. J. Hypertens. 2013:164653. doi: 10.1155/2013/164653

Gu, H., Zhong, Z., Jiang, W., Du, E., Dodel, R., Liu, J., et al. (2014). The role of choroid plexus in IVIG-induced beta-amyloid clearance. Neuroscience 270, 168 176. doi: 10.1016/j.neuroscience.2014.04.011

Haass, C., Lemere, C. A., Capell, A., Citron, M., Seubert, P., Schenk, D., et al. (1995). The Swedish mutation causes early-onset alzheimer's disease by betasecretase cleavage within the secretory pathway. Nat. Med. 1, 1291-1296. doi: 10. 1038/nm1295-1291

Hammad, S. M., Ranganathan, S., Loukinova, E., Twal, W. O., and Argraves, W. S. (1997). Interaction of apolipoprotein J-amyloid betapeptide complex with low density lipoprotein receptor related protein-2/megalin. A mechanism to prevent pathological accumulation of amyloid beta-peptide. J. Biol. Chem. 272, 18644 18649. doi: 10.1074/jbc.272.30.18644

Head, E., Pop, V., Sarsoza, F., Kayed, R., Beckett, T. L., Studzinski, C. M., et al. (2010). Amyloid-beta peptide and oligomers in the brain and cerebrospinal fluid of aged canines. J. Alzheimers Dis. 20, 637-646. doi: 10.3233/JAD-2010-1397
Hedberg, M. M., Clos, M. V., Ratia, M., Gonzalez, D., Lithner, C. U., Camps, P., et al. (2010). Effect of huprine $\mathrm{X}$ on $\beta$-amyloid, synaptophysin and $\alpha 7$ neuronal nicotinic acetylcholine receptors in the brain of 3xTg-AD and APPswe transgenic mice. Neurodegener Dis. 7, 379-388. doi: 10.1159/000287954

Iwatsubo, T., Odaka, A., Suzuki, N., Mizusawa, H., Nukina, H., and Ihara, Y. (1994). Visualization of $\mathrm{A} \beta 42(43)$ and $\mathrm{A} \beta 40$ in senile plaques with end-specific $\mathrm{A} \beta$ monoclonals: evidence that an initially deposited species is A_42(43). Neuron 13, 45-53. doi: 10.1016/0896-6273(94)90458-8

Ji, Y., Permanne, B., Sigurdsson, E. M., Holtzman, D. M., and Wisniewski, T. (2001). Amyloid beta 40/42 clearance across the blood-brain barrier following intraventricular injections in wild-type, apoE knock-out and human apoE3 or E4 expressing transgenic mice. J. Alzheimers Dis. 3, 23-30.

Johanson, C. (2003). "The choroid plexus-CSF nexus: gateway to the brain," in Neuroscience in Medicine, ed P. M. Conn (Totowa, NJ: Humana Press Inc.) 165195.

Johanson, C. E., Duncan, J. A. 3rd, Klinge, P. M., Brinker, T., Stopa, E. G., and Silverberg, G. D. (2008). Multiplicity of cerebrospinal fluid functions: new challenges in health and disease. Cerebrospinal Fluid Res. 5:10. doi: 10. 1186/1743-8454-5-10

Johanson, C., McMillan, P., Tavares, R., Spangenberger, A., Duncan, J., Silverberg, G., et al. (2004). Homeostatic capabilities of the choroid plexus epithelium in Alzheimer's disease. Cerebrospinal Fluid Res. 1:3. doi: 10.1186/17438454-1-3

Kalani, M. Y., Filippidis, A. S., and Rekate, H. L. (2012). Hydrocephalus and aquaporins: the role of aquaporin-1. Acta Neurochir. Suppl. 113, 51-54. doi: 10. 1007/978-3-7091-0923-6_11

Kalaria, R. N., and Pax, A. B. (1995). Increased collagen content of cerebral microvessels in Alzheimer's disease. Brain Res. 705, 349-352. doi: 10.1016/00068993(95)01250-8

Krzyzanowska, A., and Carro, E. (2012). Pathological alteration in the choroid plexus of Alzheimer's disease: implication for new therapy approaches. Front. Pharmacol. 3:75. doi: 10.3389/fphar.2012.00075

LaFerla, F. M., Green, K. N., and Oddo, S. (2007). Intracellular amyloid-beta in Alzheimer's disease. Nat. Rev. Neurosci. 8, 499-509. doi: 10.1038/nrn2168

Lu, Y., Barton, H. A., Leung, L., Zhang, L., Hajos-Korcsok, E., Nolan, C. E., et al. (2013). Cerebrospinal fluid $\beta$-Amyloid turnover in the mouse, dog, monkey and human evaluated by systematic quantitative analyses. Neurodegener. Dis. 12, 3650. doi: 10.1159/000341217

Maruyama, K., Tagawa, K., Kawamura, Y., Asada, H., Ishiura, S., and Obata, K. (1995). Secretion of Alzheimer beta/A4 protein (1-40) and intracellular retention of beta/A4 protein (1-42) in transfected COS cells. Biochem. Biophys. Res. Commun. 207, 971-977.

Masseguin, C., LePanse, S., Corman, B., Verbavatz, J. M., and Gabrion, J. (2005). Aging affects choroidal proteins involved in CSF production in SpragueDawley rats. Neurobiol. Aging 26, 917-927. doi: 10.1016/j.neurobiolaging.2004. 07.013

Mattsson, N., Tosun, D., Insel, P. S., Simonson, A., Jack, C. R. Jr., Beckett, L. A., et al. (2014). Association of brain amyloid- $\beta$ with cerebral perfusion and structure in Alzheimer's disease and mild cognitive impairment. Brain 137, 1550-1561. doi: 10.1093/brain/awu043

Mawuenyega, K. G., Sigurdson, W., Ovod, V., Munsell, L., Kasten, T., Morris, J. C., et al. (2010). Decreased clearance of CNS beta-amyloid in Alzheimer's disease. Science 330:1774. doi: 10.1126/science.1197623

O’Brien, R. J., and Wong, P. C. (2011). Amyloid precursor protein processing and Alzheimer's disease. Annu. Rev. Neurosci. 34, 185-204. doi: 10.1146/annurevneuro-061010-113613

Oddo, S., Caccamo, A., Kitazawa, M., Tseng, B. P., and LaFerla, F. M. (2003a) Amyloid deposition precedes tangle formation in a triple transgenic model of Alzheimer's disease. Neurobiol. Aging 24, 1063-1070. doi: 10.1016/j. neurobiolaging.2003.08.012

Oddo, S., Caccamo, A., Shepherd, J. D., Murphy, M. P., Golde, T. E., Kayed, R., et al. (2003b). Triple-transgenic model of Alzheimer's disease with plaques and tangles: intracellular Abeta and synaptic dysfunction. Neuron 39, 409-421. doi: 10.1016/s0896-6273(03)00434-3

Ohnishi, T., Hoshi, H., Nagamachi, S., Jinnouchi, S., Flores, L. G. II, Futami, S., et al. (1995). High-resolution SPECT to assess hippocampal perfusion in neuropsychiatric diseases. J. Nucl. Med. 36, 1163-1169.

Omtri, R. S., Davidson, M. W., Arumugam, B., Poduslo, J. F., and Kandimalla, K. K. (2012). Differences in the cellular uptake and intracellular itineraries of amyloid 
beta proteins 40 and 42: ramifications for the Alzheimer's drug discovery. Mol. Pharm. 9, 1887-1897. doi: 10.1021/mp200530q

Pascale, C. L., Miller, M. C., Chiu, C., Boylan, M., Caralopoulos, I. N., Gonzalez, L., et al. (2011). Amyloid-beta transporter expression at the bloodCSF barrier is age-dependent. Fluids Barriers CNS. 8:21. doi: 10.1186/20458118-8-21

Preston, J. E., Wilson, M. R., and Chen, R. L. (2005). "Aging of the choroid plexus and CSF System: implications for neurodegeneration," in The BloodCerebrospinal Fluid Barrier, eds W. Zheng and A. Chodobski (Boca Raton, FL: Taylor and Francis Books), 361-376.

Redzic, Z. B., Preston, J. E., Duncan, J. A., Chodobski, A., and SzmydyngerChodobska, J. (2005). The choroid plexus-cerebrospinal fluid system: from development to aging. Curr. Top. Dev. Biol. 71, 1-52. doi: 10.1016/s00702153(05)71001-2

Riisøen, H. (1988). Reduced prealbumin (transthyretin) in CSF of severely demented patients with Alzheimer's disease. Acta Neurol. Scand. 78, 455-459. doi: 10.1111/j.1600-0404.1988.tb03687.x

Sagare, A., Deane, R., Bell, R. D., Johnson, B., Hamm, K., Pendu, R., et al. (2007). Clearance of amyloid-beta by circulating lipoprotein receptors. Nat. Med. 13, 1029-1031. doi: 10.3410/f.1091075.544461

Sagare, A. P., Deane, R., Zetterberg, H., Wallin, A., Blennow, K., and Zlokovic, B. V. (2011). Impaired lipoprotein receptor-mediated peripheral binding of plasma amyloid- $\beta$ is an early biomarker for mild cognitive impairment preceding Alzheimer's disease. J. Alzheimer Dis. 24, 25-34. doi: 10.3233/JAD-2010-101248

Savage, M. J., Kalinina, J., Wolfe, A., Tugusheva, K., Korn, R., Cash-Mason, T., et al. (2014). A sensitive A $\beta$ oligomer assay discriminates Alzheimer's and aged control cerebrospinal fluid. J. Neurosci. 34, 2884-2897. doi: 10. 1523/JNEUROSCI.1675-13.2014

Selkoe, D. J. (2001). Alzheimer's disease: genes, proteins and therapy. Physiol. Rev. 81, 741-766. doi: 10.1007/springerreference_34009

Serot, J. M., Bene, M. C., and Faure, G. C. (2003a). Choroid plexus, aging of the brain and Alzheimer's disease. Front. Biosci. 8, 515-521. doi: 10.2741/1085

Serot, J. M., Bene, M. C., and Faure, G. C. (2003b). Normal-pressure hydrocephalus and Alzheimer disease. J. Neurosurg. 99, 797-798. doi: 10.3171/jns.2003.99.4. 0797

Serot, J. M., Christmann, D., Dubost, T., and Couturier, M. (1997). Cerebrospinal fluid transthyretin: aging and late onset alzheimer's disease. J. Neurol. Neurosurg. Psychiatry 63, 506-508. doi: 10.1136/jnnp.63.4.506

Serot, J. M., Peltier, J., Fichten, A., Ledeme, N., Bourgeois, A. M., Jouanny, P., et al. (2011). Reduced CSF turnover and decreased ventricular $A \beta 42$ levels are related. BMC Neurosci. 12:42. doi: 10.1186/1471-2202-12-42

Serot, J. M., Zmudka, J., and Jouanny, P. (2012). A possible role for CSF turnover and choroid plexus in the pathogenesis of late onset alzheimer's disease. $J$. Alzheimer Dis. 30, 17-26. doi: 10.3233/JAD-2012-111964

Silverberg, G. D., Heit, G., Huhn, S., Jaffe, R. A., Chang, S. D., Bronte-Stewart, H., et al. (2001). The cerebrospinal fluid production rate is reduced in dementia of the Alzheimer's type. Neurology 57, 1763-1766. doi: 10.1212/wnl.57.10.1763

Silverberg, G. D., Mayo, M., Saul, T., Rubenstein, E., and McGuire, D. (2003). Alzheimer's disease, normal- pressure hydrocephalus and senescent changes in CSF circulatory physiology: a hypothesis. Lancet Neurol. 2, 506-511. doi: 10. 1007/springerreference_34009

Silverberg, G. D., Messier, A. A., Miller, M. C., Machan, J. T., Majmudar, S. S., Stopa, E. G., et al. (2010a). Amyloid efflux transporter expression at the blood-brain barrier declines in normal aging. J. Neuropathol. Exp. Neurol. 69, 1034-1043. doi: 10.1097/nen.0b013e3181f46e25

Silverberg, G. D., Miller, M. C., Messier, A. A., Majmudar, S., Machan, J. T., Donahue, J. E., et al. (2010b). Amyloid deposition and influx transporter expression at the blood-brain barrier increase in normal aging. J. Neuropathol. Exp. Neurol. 69, 98-108. doi: 10.1097/nen.0b013e3181c8ad2f

Spector, R., and Johanson, C. E. (2013). Sustained choroid plexus function in human elderly and Alzheimer's disease patients. Fluids Barriers CNS 10:28. doi: $10.1186 / 2045-8118-10-28$
Sterniczuk, R., Antle, M. C., LaFerla, F. M., and Dyck, R. H. (2010). Characterization of the 3xTg-AD mouse model of Alzheimer's disease: part 2. Behavioral and cognitive changes. Brain Res. 1348, 149-155. doi: 10.1016/j. brainres.2010.06.011

Stoquart-ElSankari, S., Balédent, O., Gondry-Jouet, C., Makki, M., Godefroy, O., and Meyer, M. E. (2007). Aging effects on cerebral blood and cerebrospinal fluid flows. J. Cereb. Blood Flow Metab. 27, 1563-1572. doi: 10.1038/sj.jcbfm. 9600462

Szmydynger-Chodobska, J., Chodobski, J., and Johanson, C. E. (1994). Postnatal development changes in blood flow to choroid plexus and cerebral cortex of the rat. Am. J. Physiol. 266, 1488-1492.

Tang, Y. P., Haslam, S. Z., Conrad, S. E., and Sisk, C. L. (2004). Estrogen increases brain expression of the mRNA encoding transthyretin, an amyloid beta scavenger protein. J. Alzheimers Dis. 6, 413-420.

Tang, Z., Pi, X., Chen, F., Shi, L., Gong, H., Fu, H., et al. (2012). Fifty percent reduced-dose cerebral CT perfusion imaging of Alzheimer's disease: regional blood flow abnormalities. Am. J. Alzheimers Dis. Other Demen. 27, 267-274. doi: $10.1177 / 1533317512447885$

Thinakaran, G., and Koo, E. H. (2008). Amyloid precursor protein trafficking, processing and function. J. Biol. Chem. 283, 29615-29619. doi: 10.1074/jbc. r800019200

Tsuchiya, M., Sako, K., Yura, S., and Yonemasu, Y. (1992). Cerebral blood flow and histopathological changes after permanent bilateral carotid artery ligation in Wistar rats. Exp. Brain Res. 89, 87-92. doi: 10.1007/bf00229004

Wang, D. S., Dickson, D. W., and Malter, J. S. (2006). beta-Amyloid degradation and Alzheimer's disease. J. Biomed. Biotechnol. 3, 584-606. doi: 10.1155/JBB/ $2006 / 58406$

Wirths, O., Multhaup, G., Czech, C., Blanchard, V., Moussaoui, S., Tremp, G., et al. (2001). Intraneuronal Ab accumulation precedes plaque formation in b-amyloid precursor protein and presenilin-1 double-transgenic mice. Neurosci. Lett. 306, 116-120. doi: 10.1016/s0304-3940(01)01876-6

Wolfe, M. S., Xia, W., Ostaszewski, B. L., Diehl, T. S., Kimberly, W. T., and Selkoe, D. J. (1999). Two transmembrane aspartates in presenilin-1 required for presenilin endoproteolysis and gamma-secretase activity. Nature 398, 513-517.

Wostyn, P., Audenaert, K., and De Deyn, P. P. (2011). Choroidal proteins involved in cerebrospinal fluid production may be potential drug targets for Alzheimer's disease therapy. Perspect. Medicin. Chem. 5, 11-17. doi: 10.4137/pmc.s6509

Youmans, K. L., Tai, L. M., Kanekiyo, T., Stine, W. B. Jr., Michon, S. C., NwabuisiHeath, E., et al. (2012). Intraneuronal Abeta detection in 5xFAD mice by a new Abeta-specific antibody. Mol. Neurodegener. 7:8. doi: 10.1186/1750-1326-7-8

Zwolinski, B. J., Eyring, H., and Reese, C. E. (1948). Diffusion and membrane permeability. J. Phys. Chem. 53, 1426-1453.

Conflict of Interest Statement: The authors declare that the research was conducted in the absence of any commercial or financial relationships that could be construed as a potential conflict of interest.

Received: 25 September 2014; accepted: 12 January 2015; published online: 06 February 2015.

Citation: González-Marrero I, Giménez-Llort L, Johanson CE, Carmona-Calero EM, Castañeyra-Ruiz L, Brito-Armas JM, Castañeyra Perdomo A and CastroFuentes $R$ (2015) Choroid plexus dysfunction impairs beta-amyloid clearance in a triple transgenic mouse model of Alzheimer's disease. Front. Cell. Neurosci. 9:17. doi: $10.3389 /$ fncel.2015.00017

This article was submitted to the journal Frontiers in Cellular Neuroscience.

Copyright $\odot 2015$ González-Marrero, Giménez-Llort, Johanson, Carmona-Calero, Castañeyra-Ruiz, Brito-Armas, Castañeyra Perdomo and Castro-Fuentes. This is an open-access article distributed under the terms of the Creative Commons Attribution License (CC BY). The use, distribution and reproduction in other forums is permitted, provided the original author(s) or licensor are credited and that the original publication in this journal is cited, in accordance with accepted academic practice. No use, distribution or reproduction is permitted which does not comply with these terms. 